\title{
Campesinos, emociones y tentativas de resistencia armada a la dictadura empresarial-militar de Brasil
}

\author{
Fabricio Teló \\ Universidad Federal Rural de Rio de Janeiro, Rio de Janeiro, Brasil \\ Email: telo.fabricio@gmail.com
}

\begin{abstract}
Resumen: El propósito de este trabajo es analizar la relación entre militantes de organizaciones armadas y campesinos durante la dictadura militar en Brasil (1964-1985).La atención se centra en cómo las emociones han interferido en los procesos de participación, desconexión y no participación de los campesinos en los intentos de formar grupos guerrilleros rurales, ya que las emociones son una importante forma de comprender mejor las acciones colectivas y la violencia política. El caso específico analizado en este artículo es el esfuerzo iniciado por el Comando de Liberación Nacional (Colina) en el campo del estado de Río de Janeiro y finalizado por la Vanguardia Revolucionaria Armada Palmares (VARPalmares) en la región fronteriza entre Maranhão y Tocantins. El estudio utiliza la historia oral como su metodología principal y se basa en entrevistas con sobrevivientes de ese período. El análisis también fue completado con archivos de la policía política.
\end{abstract}

Palabras-clave: Campesinos; lucha armada; represión; emociones; sociología.

\section{Peasants, emotions and attempts of armed resistance to the business-military dictatorship in Brazil}

\begin{abstract}
The purpose of this paper is to analyze the relationship between militants of armed organizations and peasants during the military dictatorship in Brazil (1964-1985).The focus is on how emotions have interfered with peasants' processes of participation, disconnection and non-participation in attempts to form rural guerrilla groups, as emotions are an important way to better understand collective actions and political violence. The specific case analyzed in this article is the effort initiated by the National Liberation Command (Colina) in the countryside of the state of Rio de Janeiro and finalized by the Vanguardia Revolucionaria Armada Palmares (VAR-Palmares) in the border region between Maranhão and Tocantins. The study uses oral history as its main methodology and is based on interviews with survivors of that period. The analysis was also completed with files from the political police.
\end{abstract}

Keywords: Peasants, armed struggle, repression, emotions, sociology

\section{Camponeses, emoções e tentativas de resistência armada à ditadura empresarial-militar no Brasil}

Resumo: O objetivo deste artigo é analisar a relação entre militantes de organizações armadas e camponeses durante a ditadura militar no Brasil (1964-1985).O foco é sobre como as emoções interferiram nos processos de engajamento, desengajamento e não-engajamento dos camponeses em tentativas de formar grupos guerrilheiros rurais, uma vez que as emoções são uma forma importante para compreender melhor a ação coletiva e da violência política. O caso específico discutido no artigo é a tentativa iniciada pelo Comando de Libertação Nacional (Colina) na área do Rio de Janeiro e continuado pela Vanguarda Armada Revolucionária Palmares (VAR-Palmares) na região de fronteira entre Maranhão e Tocantins.O estudo utiliza a história oral como sua principal metodologia, baseada em entrevistas com sobreviventes daquele período. A análise também foi informada por arquivos da polícia política. 
Palavras-chave: Camponeses; luta armada; repressão; emoções; sociologia

\section{Introducción}

Entre 1964 y 1985, Brasil vivió un período de dictadura marcado por la represión de los movimientos sociales y la clase trabajadora. Como señala Dreifuss (1981), uno de los temas centrales del debate público en los años previos al golpe fue la cuestión agraria (concentración de la tierra y conflictos para acceder a ella). Varias organizaciones campesinas exigieron una distribución más equitativa de la tierra y, en consecuencia, los grandes terratenientes contribuyeron a las negociaciones políticas dedicadas a derrocar al presidente João Goulart. En el campo, como resultado de la dictadura, miles de familias fueron expulsadas violentamente de las tierras que ocupaban. Varias haciendas, que fueron desapropiadas en años anteriores para la reforma agraria, fueron devueltas a sus antiguos dueños. Muchos líderes fueron arrestados, asesinados u obligados a huir. En este contexto, el miedo estaba muy extendido en la vida de las personas, especialmente en grupos subalternos. A pesar de esto, se llevaron a cabo varias iniciativas de resistencia, desde el sindicalismo hasta la lucha armada.

Dada la influencia de las revoluciones del siglo XX -donde las áreas rurales eran sitios estratégicos para el enfrentamiento armado, especialmente en China (1949) y Cuba (1959)- los líderes de la mayoría de las organizaciones brasileñas de izquierda establecieron como estrategia política que el campo debería ser el espacio para iniciar su intento de revolución. Por lo tanto, aunque la lucha armada contra la dictadura en Brasil tuvo lugar principalmente en áreas urbanas (Ridenti, 2010), la mayoría de las organizaciones consideraron que las áreas rurales eran sitios más adecuados para gestar una revolución. Para este fin, los militantes necesitaban establecer conexiones con los campesinos y movilizarlos a participar en las luchas políticas de sus organizaciones, la mayoría armadas.

Partiendo de este contexto, el objetivo de este artículo es analizar el impacto de las emociones en esas relaciones entre militantes de organizaciones guerrilleras y campesinos sin experiencia previa en la lucha arma$\mathrm{da}^{1}$. Esta pregunta está parcialmente inspirada por Wolf (1984), quien desarrolló un estudio similar con respecto a México, Rusia, China, Argelia, Cuba y Vietnam. Sus preguntas fueron:

¿Quién es, entonces, el que habla al campesino y qué es lo que comunican, lo que mueve al campesino a la acción política violenta? Los campesinos albergan un profundo sentido de injusticia, pero a este sentido de injusticia se le debe dar forma y expresión en la organización antes de que pueda activarse en la escena política; y es obvio que no todos los agitadores calificados encontrarán una audiencia de bienvenida en los círculos de las aldeas tradicionalmente sospechosas, especialmente cuando provienen de la ciudad. ¿Qué circunstancias y qué grupos de personas resultarán propicias para el establecimiento de tal comunicación? (Wolf, 1984, p.13).

Con foco más específico en el rol de las emociones en esos procesos, Wood (2001) realizó estudio semejante con respecto a la participación campesina en la lucha armada en El Salvador y analizó cómo los beneficios emocionales (por ejemplo, la alegría y el orgullo) consecuencia de la implicación en la lucha eran muchas veces más importantes que ciertos beneficios materiales, como el acceso a la tierra o más derechos. La lucha en sí misma era fuente de dignidad y respecto. Las cuestiones desarrolladas por Della Porta (1995; 1998), Jasper (1998), Goodwin y Pfaff (2001), Wood (2001), Bohamón (2006), Quirós (2010) y Flam (2015) sobre la influencia de la dimensión emocional en las dinámicas de protesta también nortearon la elaboración de este artículo.

La tentativa más importante y más conocida de desarrollar una guerrilla rural en Brasil fue la realizada por el Partido Comunista de Brasil (PCdoB) en la región de Araguaia, situada entre varios estados de la Amazonia brasileña. Otras organizaciones también intentaron formar sus propias guerrillas, pero no se han estudiado tan extensamente como la de Araguaia. Este artículo llama la atención sobre un intento iniciado por el Comando de Liberación Nacional (Colina) en el municipio de Cachoeiras de Macacu (en el estado de Río de Janeiro) y 
concluido por la Vanguardia Revolucionaria Armada Palmares (VAR-Palmares) en los municipios de Imperatriz (en el estado de Maranhão), e Itaguatins (en el estado de Tocantins), ambos en el norte de Brasil. La razón para elegir el caso Colina/VAR-Palmares se debe a que una investigación anterior sobre violaciones de derechos humanos sufridas por campesinos en el estado de Río de Janeiro mostró que este hecho político aún no era bien conocido, incluso por investigadores locales.

Dado que los recuerdos de los sobrevivientes son la evidencia principal con la que tenemos que trabajar, la metodología de la historia oral fue fundamental para el desarrollo de la investigación. Se desarrollaron entrevistas y conversaciones informales con actores sociales involucrados en el caso Colina/VAR-Palmares y otras con campesinos que decidieron no involucrarse. Desafortunadamente, entre los campesinos que participaron en los entrenamientos de guerrilla, solo uno sigue vivo y fue entrevistado tres veces. Además de él, también fueron entrevistadas tres de sus viudas.

La investigación enfrentó tres dificultades principales: 1) la mayoría de los campesinos que participaron en los intentos revolucionarios ya han fallecido; 2) los testimonios de los militantes arrestados se dieron bajo tortura, por lo que es necesario tener especial cuidado al analizar la información que contienen; 3) los que siguen vivos evitan compartir todos los detalles de sus historias, por temor al castigo por su participación en las organizaciones armadas, especialmente después de 2018, con la elección de un presidente que defiende el legado de la dictadura² .

\section{Campesinos y militantes de la lucha armada: el caso Colina - Var/Palmares}

Colina era una organización formada por militantes que habían dejado una anterior, llamada Polop (Organización Revolucionaria Marxista-Leninista - Política Operaria, o Organização Revolucionária MarxistaLeninista - Política Operária, en portugués). La razón principal de esta disidencia fue que Polop había estado en algún lugar entre la lucha de masas (una estrategia no centrada en las armas, sino en los intentos de cambiar los marcos políticos de la población) y la preparación de la lucha armada. Los disidentes defendieron la concentración de la segunda manera, el foquismo ${ }^{3}$, una estrategia revolucionaria teorizada por Debray (1967) basada en la Revolución Cubana. Creían que estaban dadas las condiciones necesarias para desencadenar la lucha armada y que el carácter de la guerrilla debía ser rural ${ }^{4}$ (Sales, 2005).

Por esta razón, intentaron formar un grupo guerrillero en Nova Ribeira, una pequeña localidad del municipio de Cachoeiras de Macacu, cerca de la región metropolitana de Río de Janeiro. La razón para elegir esta ubicación es que antes del golpe de estado de 1964, los campesinos de esa región se movilizaron ampliamente en las luchas por la tierra y, por lo tanto, se les consideraba más propicios a volver a participar en iniciativas colectivas para provocar un cambio social. El grupo se formó sobre la base de un vínculo de amistad entre los dos líderes principales del proceso: un cura (Alexandre) y una trabajadora social (Maria), que habían se conocido previamente en Pernambuco, donde estudiaron juntos.

Maria comenzó una relación con un agrónomo (José) que compartía apartamento con militantes que ya estaban participando de Colina. Como resultado, ella se unió a la organización e invitó también a Alexandre, de forma que fue posible establecer un vínculo entre Colina y los campesinos de Nova Ribeira, puesto que Alexandre tenía una relación cercana con ellos. El cura y varios militantes de Colina iniciaron sus actividades a fines de 1968con un grupo de unos 20 campesinos. Las principales actividades fueron clases para enseñar a los campesinos a leer y escribir, misas (rituales católicos) y discusiones sobre el derecho a la tierra, un problema común en ese momento.

En mayo de 1969, el Ejército -que pretendía arrestar a uno de los campesinos que habían liderado las movilizaciones anteriores del 64- entró en el área donde vivían los campesinos de Nova Ribeira. Como consecuencia, el resto de los integrantes del grupo huyeron. La mayoría de ellos se desconectaron del proyecto guerrillero en ese momento, pero tres familias decidieron continuar. Se escondieron durante unos meses en una ciudad cercana a Cachoeiras de Macacu, antes de que la organización los llevara a Imperatriz, una ciudad en el sur de Maranhão (un estado en la región norte de Brasil). En esto momento, la organización Colina se había 
unido con otra organización (La Vanguardia Popular Revolucionaria - VPR) y, como resultado, crearon la Vanguardia Armada Revolucionaria Palmares (VAR-Palmares) (Gorender, 1987). En esta región, llamada de Bico do Papagaio, la organización tenía otros militantes en ciudades cercanas que también ejercían un trabajo de aproximación a los campesinos. Después de estar en esta región durante aproximadamente un año, el Ejército los reprimió nuevamente, los arrestó a casi todos y acabó con el proyecto de formar un grupo guerrillero.

Con el fin de contribuir con el debate sobre la conexión entre las emociones y la protesta, este artículo desarrolla las siguientes ideas: 1) las emociones recíprocas, especialmente el vínculo entre la amistad y el reclutamiento de los campesinos; 2) el placer de formar parte de la organización; 3) el resentimiento por haber perdido a un miembro de la familia; 4) el efecto del miedo a convertirse en una víctima de la represión y las emociones morales.

\section{Las emociones recíprocas}

Hacerse amigos y queridos de los campesinos ha sido el principal objetivo de los militantes que buscaban movilizarlos en la lucha revolucionaria. Para tanto, una estrategia de las organizaciones armadas era estimular la creación de emociones recíprocas (Jasper, 1998) de afecto y lealtad. Flam (2015) argumenta que, aunque los investigadores a menudo sostienen que la solidaridad, la amistad, la camaradería o los lazos familiares mantienen los movimientos sociales, todavía falta un esfuerzo mayor en el sentido de contextualizar y de explorar las correlaciones emocionales de estos conceptos. Para la autora, es necesario, profundizar la sustancia de estas relaciones, "señalando las condiciones bajo las cuales emergen, prosperan y se ven amenazadas" (Ibid, p. 269). Es lo que nos propusimos a hacer a partir de algunos ejemplos.

Antonio era un campesino del Estado de Rio Grande do Norte que había migrado a la municipalidad de Cachoeiras de Macacu, en el Estado de Rio de Janeiro, porque había oído hablar que allá había tierras disponibles. Su formación cultural estaba marcada por una religiosidad católica muy fuerte, lo que favoreció la aproximación con el cura Alexandre, quien relató cómo los dos empezaron su relación de amistad: en el día de Santa Ana, la patrona de la parroquia donde vivían, Antonio fue a la iglesia a bautizar a un niño, ya que era costumbre de los campesinos aprovechar la fecha para hacer este ritual. Como la familia de Antonio llegó tarde, Alexandre ya estaba cansado y estaba haciendo el bautismo de manera relajada. Cuando Antonio notó que el sacerdote no estaba conduciendo el ritual adecuadamente, hizo un comentario crítico. El cura quedó impresionado por el comentario, que lo estimuló a dirigir la celebración adecuadamente a partir de aquel momento. Se dio cuenta de que el campesino era valiente y crítico y, por lo tanto, una persona interesante con la que entablar amistad: "si este hombre es lo suficientemente valiente como para desafiar al cura [una autoridad, en general, en el campo brasileño], este hombre es bueno", pensó Alexandre, que empezó a frecuentar seguidamente la casa de Antonio y a hacerse amigo también de los hijos, yernos, nueras y vecinos del campesino (Alexandre, entrevista en el 5 de mayo de 2015, Rio de Janeiro/RJ).

La proximidad fue creciendo y el cura empezó a dedicar dos días por semana de su tiempo para trabajar con los agricultores en los cultivos. De la relación de amistad surgió la idea de comenzaren un emprendimiento juntos e iniciaron la construcción de una casa para producir harina. Aunque no se concluyese la construcción, la iniciativa sedimentó aún más la relación de apoyo mutuo entre el sacerdote y la familia de Antonio. Además de eso, decidieron también construir una capilla para la comunidad y la hicieron colectivamente. Roberta, hija de Antonio, relata que su padre estaba muy animado con la propuesta: plantó árboles ornamentales alrededor del templo y ofreció la madera necesaria para el altar, una de las partes centrales de la iglesia (Roberta, entrevista en el 18 de septiembre de 2015, Cachoeiras de Macacu/RJ).

Alexandre también conquisto el respecto de los campesinos a través de la mediación de problemas de regularización de tierras que gran parte de ellos tenían. Como se trataba de un área de asentamiento creado en gobiernos anteriores al de los militares, el instituto de reforma agraria creado por la dictadura planeaba expulsar a los campesinos que no tenían la documentación regularizada. Cuando Alexandre identificó este problema, contactó al obispo y al alcalde de la municipalidad para encontrar una solución para el caso. Los campesinos interpretaron este acto como una expresión de la consideración del cura hacia ellos y comenzaron a aceptar más 
fácilmente las invitaciones de Alexandre para involucrarse en sus actividades (Alexandre, testimonio manuscrito, firmado en 10/11/1971, en el DOPS/GB, Acción Penal 01/72, BNM_057, p. 881).

Tales emociones recíprocas constituyeron la base a partir de la cual se creó el grupo de entrenamiento de guerrilla en la comunidad. Antonio y sus familiares ayudaron a Alexandre a reclutar otros campesinos de la localidad. Cuando la invitación venía del cura, con el apoyo de un igual (un vecino), los convidados se sentían más estimulados o abiertos para participar en las actividades de formación política promovidas por Alexandre, María, José y otros militantes de Colina (Alexandre, entrevista en el 5 de mayo de 2015, Rio de Janeiro/RJ).

Otro ejemplo que ilustra el papel de la reciprocidad de afectos en el reclutamiento es João, un campesino de la municipalidad de Itaguatins, en el Estado de Tocantins, región del Bico do Papagaio. Él relató que comenzó a participar del grupo de entrenamiento guerrillero gracias a la amistad que tenía con uno de los miembros de la organización (Paulo) que, a mediados de 1969, había ido a vivir en la región con el objetivo de movilizar a los campesinos a la formación del grupo guerrillero. Siguiendo la influencia de Giap $(1971)^{5}$, que aconsejaba a las organizaciones a conquistar "la confianza y el afecto" de la población, los militantes procuraban colocarse siempre al servicio de los campesinos ayudándolos lo máximo posible. Paulo solía visitar a personas enfermas, les proporcionaba medicamentos, les ayudaba con el transporte y donaba recursos a los necesitados, especialmente alimentos (João, entrevistas en el 5 de marzo de 2016 y 26 de noviembre de 2018, Itaguatins /TO).

Por causa de estas actitudes de Paulo, João le encontró como una buena persona, y por lo tanto confiable y de quien nadie esperaría algo malo. Empezó a convivir más con Paulo y se tornó más abierto a oír lo que el militante le hablaba. Así que discordó de la acusación hecha por los militares de que la organización practicaba el terrorismo y se tornó un fiel seguidor del grupo. La relación de amistad entre los dos se fortaleció después que Paulo llevó a la hija de João al hospital cuando estaba enferma. El campesino cree que, si no fuera por el militante, su hija probablemente no estaría viva, ya que él no tendría condiciones de llevarla. Además de la relación de amistad, que se fortaleció después de este momento, se creó entre los dos una relación de reciprocidad en la que el campesino sentía la necesidad de retribuir al militante por haberle salvado la vida a su hija (João, entrevistas en el 5 y 6 de marzo de 2016, Itaguatins/TO).

Esta relación se construyó en una región de reciente ocupación con una población mayoritariamente inmigrante, lo que facilitó la inserción de los militantes, que fueron aceptados fácilmente como nuevos habitantes entre otros recién llegados. Fue una elección estratégica de la organización ${ }^{6}$. Paulo habría tenido muchas más dificultades para crear una relación de confianza con João y con el resto si hubiera ido para una región de ocupación más antigua. Las condiciones sociales de los campesinos eran de extrema precariedad. La imposibilidad de João de llevar a su hija al hospital es un ejemplo de las dificultades por las que pasaban. La única opción de la población local era colocar al enferme en una especie de hamaca y transportarlo a pie, pero la ciudad estaba a días de caminata y el viaje era peligroso.

Estos lazos de amistad son analizados por Jasper (1998) como emociones recíprocas dado el cambio de afectos en ellos presentes y la "extremadamente importante confianza que los miembros empiezan a tener unos por los otros" (Ibid, p. 187). Para el autor, esos cambios son una fuente importante de identificación con el movimiento. En su obra, el autor enfatiza la reciprocidad creada entre los militantes una vez ya comprometidos con la causa. No obstante, en los casos relatados en este artículo, las emociones recíprocas fueron el elemento central desde el momento de decisión de adhesión al grupo.

Della Porta (1998) también analiza las emociones cuando trata de las motivaciones individuales de las personas que se implicaron en organizaciones clandestinas en Italia y Alemania en la segunda mitad del siglo XX. De acuerdo con la autora, si ya en los movimientos sociales en general los vínculos afectivos son un importante elemento de movilización y compromiso, en el contexto de las organizaciones clandestinas, como es el caso de Colina y VAR-Palmares, esos vínculos ganan una relevancia aún mayor, ya que los lazos fuertes entre las personas son el principal mecanismo por medio del cual las organizaciones pueden promover la adhesión de nuevos miembros y ampliar su tamaño. Bahamón (2006, p. 180) identificó motivaciones semejantes cuando estudió el ingreso de jóvenes en las Fuerzas Armadas Revolucionarias de Colombia (FARC): "la solidaridad, la 
lealtad y la camaradería son emociones que constituyen por sí mismas motivos preponderantes para participar en el grupo armado o para permanecer en él”.

Sin embargo, ni siempre las tentativas de creación de vínculos afectivos tuvieron éxito. De hecho, en el caso aquí analizado, la mayor parte de estos intentos fracasaron. Claudio, vecino de João, es un ejemplo. De acuerdo con su relato, cuando Paulo llegó a la comunidad, Claudio desconfió de las intenciones del recién llegado, ya que percibió que Paulo era alguien distinto: "Me extrañó porque la gente percibe cuando alguien es inteligente y sabio. ¿Qué hace este hombre aquí entre personas débiles y sin sabiduría?” Este recelo provocó dudas en Claudio acerca de Paulo e impidió que se crease una relación de confianza entre los dos. Como resultado, Claudio no se involucró con el grupo (Claudio, entrevista en el 19 de noviembre de 2018, Itaguatins/TO).

Según Della Porta (1998), la condición de ilegalidad de estas organizaciones impone la necesidad de un secretismo que se basa en relaciones de complicidad que necesitan sostenerse en una profunda confianza entre los sujetos involucrados. Paulo nunca habló de la estrategia guerrillera a Claudio y solo empezó a hablar de la idea de la lucha armada a João después de que ya habían construido esta relación de confianza resultante de su amistad. Sin eso, Paulo estaría poniendo su seguridad y la de sus compañeros en peligro.

Para la autora, el grado de intensidad de esos lazos interfiere también en el nivel de importancia que los individuos dan a la política en sus vidas: cuanto más denso el vínculo de amistad entre los militantes de las organizaciones clandestinas, más valor ganan las actividades políticas. Dicho de otra forma, las relaciones de amistad dentro de un movimiento favorecen la transición de posiciones moderadas a posiciones más radicales. Fue lo que ocurrió con los campesinos del caso que nos ocupa. Personas que hasta entonces venían actuando políticamente por la vía de la ocupación de tierras o de recogidas de firmas, asumieron la vía armada.

Desde una perspectiva filosófica, Ortega (2000) ${ }^{7}$ también analiza los vínculos entre amistad, política y emociones. Para él, hacer amigos es una forma de producir nuevas formas de subjetividad y acción, y por lo tanto, una manera de reinventar la política. Al comparar conexiones entre individuos que existen en las familias y el vínculo entre amigos, el autor argumenta que este último brinda a la persona la posibilidad de tener contacto, no solo dentro de un espacio privado (el entorno familiar), sino también en la esfera pública, lo que es fundamental para desarrollar actividades políticas. La amistad, por lo tanto, puede ser un ejercicio de la políti$\mathrm{ca}^{8} \mathrm{y}$, en ese sentido, la simple apertura que João le dio a Paulo para que fuera su amigo podría ser vista como un proceso mediante el cual, al ponerse en contacto con un desconocido, ambos ejercitaron su libertad e hicieron política.

\section{El placer del involucramiento}

Como los militantes llegaban en las comunidades con más recursos ${ }^{9}$, tenían más facilidad para ponerse al servicio de los campesinos y ayudarlos en estos momentos de dificultad, como muestra el capítulo anterior. En una entrevista con un antiguo residente de la comunidad de Nova Ribeira, preguntamos qué motivó a los campesinos a unirse a la invitación para formar parte del grupo. Él respondió: "Les dieron una nueva bicicleta, una nueva escopeta, un nuevo rifle..." (antiguo residente, entrevista en el 18 de noviembre de 2014, Cachoeiras de Macacu/RJ). Una visión economicista y utilitarista del proceso tomaría esas informaciones para interpretar la participación política de los campesinos en las organizaciones armadas como una búsqueda de la satisfacción de sus intereses o necesidades. El enfoque utilizado aquí, sin embargo, trata de superar las dicotomías entre intereses y desintereses; razón y emoción.

Jasper, Godwin y Poletta (2001) sostienen que la superación de esa dicotomía es importante para mejor comprender la influencia de las emociones en la vida social. Según los autores, las emociones son un aspecto de todas las acciones y relaciones sociales; "acompañan tanto los actos racionales como los irracionales, tanto las experiencias positivas como las negativas” (2001, p. 9).

Como señala Quirós (2009), la literatura sobre los movimientos sociales está marcada por una oposición entre la economía y la política, así como entre el economicismo y el moralismo. Al emprender una etnografía 
sobre los movimientos laborales en Argentina, la investigadora mostró que la búsqueda de donaciones por sí sola (el interés económico) no era suficiente para explicar por qué los trabajadores se involucraron con una organización. Hubo varias interacciones personales, emociones y preocupaciones morales que también jugaron un papel central en los procesos. Para sostener su argumentación, la autora propone una interpretación del clásico "Ensayo sobre el don" (Mauss, 2003) que destaca el hecho de que la obligatoriedad y el interese del retribuir no anulan la voluntariedad y el desinterese del acto. No es posible afirmar, por lo tanto, que la adhesión de João, Antonio y de los demás campesinos a la organización fue una simple retribución interesada en lo que los militantes les donaban o a partir de las ayudas que les prestaban; tampoco fue un compromiso puramente ideológico. Las propias categorías empleadas no dan cuenta de la complexidad de los procesos. Una sociología de las emociones puede contribuir para avanzar en este aspecto.

El concepto de "placer de la protesta" (Jasper, 1998), por ejemplo, permite observar como las personas se involucran, se mantienen involucradas o mismo fortalecen su compromiso político en función del placer que sienten al tomar parte en las actividades de la organización en la que participan. Los placeres de la protesta están vinculados también a las emociones colectivas, especialmente las recíprocas, analizadas anteriormente: “los más obvios son los placeres de estar con las personas que nos gustan, de muchas maneras” (Ibid, p. 188). No fueron solo las donaciones de bicicletas y armas lo que movilizó a los campesinos de Nova Ribeira para entrar en el grupo liderado por el sacerdote. El entusiasmo con la construcción de la casa de harina, la alegría de ver la capilla lista y el respecto creado por la actuación de Alexandre a favor de los vulnerables alimentó un intercambio intenso de afectos entre ellos y el cura y servían como estímulo a la participación en las actividades por él promovidas.

Quirós (2010) utilizó una idea semejante mediante el concepto de "placer de hacer” (sentirse bien mientras se hace algo), de Florence Weber, como una dimensión fundamental para superar las dicotomías anteriormente citadas y comprender mejor el proceso de compromiso político. Sentirse bien en medio de las personas con las que se trata y sentirse feliz por hacer algo en beneficio del colectivo fueron elementos que Quirós identificó como esenciales para que los trabajadores se involucrasen en las protestas y que aparecieron también durante las conversaciones informales con João, cuando hablaba con nostalgia sobre su amistad con Paulo, destacando los buenos y felices momentos que tuvieron juntos, especialmente en las visitas, almuerzos y cazas.

De manera similar, Wood (2001) identifica el placer como un sentimiento fundamental para los campesinos que participaron en las luchas de guerrillas en El Salvador durante la década de 1980: "debido a que el acceso a la tierra no dependía de la participación, sostengo que el placer de la agencia (o "beneficios emocionales”) fue cada vez más la motivación principal de los participantes (para mantenerse comprometidos en la lucha)" (Ibid, p. 272). Logros como el acceso a la tierra y la creación de cooperativas fueron percibidos como fuentes de orgullo por los campesinos salvadoreños. En el caso de Colina/Var-Palmares, según las conversaciones con los entrevistados, los "beneficios emocionales", como el "placer de la agencia”, también constituyeron un factor motivador para la adhesión a la organización. Sin embargo, de manera distinta del caso salvadoreño, para los campesinos del caso analizado en este artículo, los beneficios se basaron más en la camaradería y la fidelidad, que en el orgullo por algún logro, ya que el movimiento fue reprimido poco tiempo después de la creación del grupo.

\section{El resentimiento por perder un familiar}

Antonio tenía un hijo (Afonso) que también estaba involucrado en el grupo de entrenamiento militar en Nova Ribeira. En mayo de 1969, cuando el Ejército se adentró en el territorio donde el grupo vivía, hubo tiroteos y Afonso murió. Esto provocó en Antonio una profunda ira contra el Ejército, lo que constituyó una motivación para que él profundizara su compromiso con la organización y pusiera aún más energía en actividades dirigidas a acabar con el gobierno responsable por el asesinato de su hijo. José, marido de María, militante de Colina, relató: "Pedro estaba tan conmovido por este hecho que quería matar al hombre [militar] acusado de ser el asesino" (José, entrevista en el 13 de enero de 2015, São Paulo/SP). 
De hecho, como lo señalaron Jasper y Godwin (2006, p. 630), “cuando se considera que la represión es extremadamente injusta, es más probable que la indignación amplíe la protesta, pero tiene que superar el miedo para hacerlo". Y cuando la represión apunta a un miembro de la familia, la indignación tiende a ser aún más fuerte. Pedro ya estaba involucrado en los entrenamientos de guerrilla y, según Alexandre, era considerado un hombre intrépido, lo que facilitó este proceso de profundizar en su compromiso con el proyecto de la guerrilla. Della Porta (1995), en su investigación sobre las organizaciones clandestinas de Alemania e Italia, también identificó la represión policial como un elemento promotor de rabia e indignación, lo que fortaleció las ganas de los militantes de luchar contra el gobierno y como una justificativa para el uso de la violencia política.

Sin embargo, después de ser arrestado en 1971 en Imperatriz/MA, este sentimiento contribuyó a que Antonio se desvinculase de la organización. Mientras estaban en la cárcel, los militares solían decirle que Alexandre era el culpado de la muerte de su hijo, por invitarlos a participar en los entrenamientos de guerrilleros. El ex sacerdote dijo: "Lograron catequizar a Antonio diciendo que yo le llevé por el mal camino Los militares le decían: ‘estabas bien... El sacerdote fue quién te llevó por el camino equivocado. Te ha engañado’ [...]. Y Antonio terminó odiándome” (Alexandre, entrevista en el 5 de mayo de 2015, Rio de Janeiro/RJ).

Ese relato parece mostrar que un nuevo objeto de ira fue agregado después de la prisión: Antonio no estaba solo molesto con el Ejército, sino también contra su entonces compañero Alexandre. Este ejemplo apunta a que, en algunas situaciones, ciertas emociones pueden estimular un compromiso más profundo por algún tiempo, pero pueden cambiar dependiendo de los hechos que van ocurriendo a lo largo del tiempo y pueden generar diferentes impactos en las posturas políticas del individuo.

\section{El miedo y las emociones morales}

El temor a convertirse en un objetivo de represión como resultado del compromiso político interfiere tanto en las decisiones de involucrarse en la organización como de permanecer comprometido o renunciar. Roberta, hija de Antonio y viuda de Francisco (otro campesino que se involucró en el grupo), habló sobre la actuación de su esposo: "Francisco era un hombre que no tenía miedo de nada”, lo que sugiere que el coraje era una condición para convertirse en un militante de la lucha armada (Roberta, entrevista en el 18 de septiembre de 2014, Cachoeiras de Macacu/RJ). Por otro lado, un vecino que no se involucró en la iniciativa afirmó: "No tuve nada que ver con esto [el entrenamiento de la guerrilla]. Tú sabes cómo es. Tenemos miedo” (antiguo residente, entrevista en el 18 de noviembre de 2014, Cachoeiras de Macacu/RJ).

João también temía morir o ser arrestado, pero siguió comprometido porque, según él, “el entusiasmo y la esperanza eran mayores que el miedo” y tenía esperanza de que la revolución acontecería, que iría "entrar en el juego y ganar”. Además de eso, el hecho de que tenía práctica con el uso de escopetas, porque solía cazar en el bosque, le permitía sentirse más empoderado y fortalecer su esperanza de vencer: "en este punto (el manejo de las armas) yo era más avanzado. (...). Yo no pensaba que iba morir o ir al cárcel” (João, entrevista en el 20 de noviembre de 2018, Itaguatins/TO). Inspirados especialmente en la Revolución Cubana, los militantes compartían de tal esperanza. Creían que la lucha armada era como "una chispa en la pradera seca”: bastaba encender y, así como el fuego, se propagaría fácilmente ${ }^{10}$.

El miedo también fue central para el alejamiento de aquellos que ya estaban comprometidos. En Itaguatins/ TO, Lucas (primo de João) comenzó a participar en las actividades de la organización, pero luego que conoció la estrategia de la guerrilla, se dio cuenta de los riesgos que enfrentaría como guerrillero y decidió renunciar. “Asistió a dos o tres reuniones, se asustó y renunció” (João, entrevista en el 6 de marzo de 2016, Itaguatins/TO). $\mathrm{Al}$ analizar cuatro décadas después el compromiso de su familia en el grupo, Roberta demuestra cierto arrepentimiento por no haber hecho una lectura de la realidad como hizo el primo de João: "nosotros no entendíamos la gravedad de la situación. Yo tenía 16 años de edad. Si fuera hoy, yo no dejaría que mi familia se involucrase" (Roberta, entrevista en el 18 de septiembre de 2014, Cachoeiras de Macacu/RJ).

Roberta también declaró que, antes de ser arrestado, Francisco ya mostraba señales de que, a pesar de su coraje, estaba pensando en abandonar la organización, dado el riesgo cada vez más inminente de ser atrapado: 
"[él] estaba viendo el fracaso de la organización, muchas personas cayendo: algunos presos, otros muertos. 'Estoy poniendo en riesgo la vida de mi gente. Ya perdí a mi cuñado. Mi cuñada se volvió loca. No sé qué hacer. No quiero continuar más'” (Roberta, entrevista en el 11 de septiembre de 2015, Cachoeiras de Macacu/RJ). Este es un buen ejemplo de la conjugación entre razón y emoción. Francisco estaba sintiendo la emoción de estar en riesgo y, al mismo tiempo, estaba usando su razón para percibir que debería abandonar la organización para salvar su vida y la de su familia.

Además, si se considera el testimonio escrito por Alexandre al ejército, el miedo parece haber sido un aspecto que los militantes tomaban en cuenta para definir qué tipo de acciones emprenderían. Según lo que escribió, el grupo estaba planeando robar un banco y una fábrica, pero no lo hizo, debido al "temor de emprender este tipo de actividad" y porque "sus creencias cristianas no se lo permitieron" (Alexandre, testimonio escrito firmado el 10 de noviembre de 1971 en DOPS/GB, Acción Penal 01/72, BNM_057, p. 883). Dado el hecho de que esta información se proporcionó bajo tortura, es difícil de afirmar que las razones por las que no llevaron a cabo este plan fueron realmente las señaladas por el cura en su testimonio. En cualquier caso, aunque puede haber otras razones, esta fue la explicación elegida en ese momento para describir la situación, lo que significa que el miedo estaba de alguna manera presente en su práctica militante. El miedo, por lo tanto, como lo señala Barbalet (1998), no siempre es perjudicial para los movimientos sociales. A veces es una fuente de discernimiento para definir mejor las estrategias de acción sin poner en riesgo la vida del militante, o si no fuera el caso, fue una justificación para la utilización de una determinada narrativa en el momento de la tortura.

Es por eso que Godwin y Pfaff (2001) enfatizan la importancia de hablar sobre la gestión (en lugar de la eliminación) del miedo en los procesos de acción colectiva, especialmente en situaciones de alto riesgo. El desafío, entonces, es encontrar mecanismos adecuados de estímulo para garantizar el compromiso colectivo con la causa y, al mismo tiempo, asegurarse de que este compromiso se realice de manera adecuada. Además, tanto el individuo como el colectivo deben propiciar una gestión del miedo, basándose en las interacciones entre los miembros. La estrategia de Paulo de invitar a los campesinos a cazar puede ser leída, por tanto, como uno de esos "mecanismos de motivación" (encouragement en el texto original) que citan los autores para manejar el miedo, puesto que en los momentos de caza, la persona va desarrollando la práctica del uso de las armas, la vivencia en la selva y, lo más importante, se familiariza con un ambiente similar al de una guerrilla.

En su análisis de la participación política de los campesinos salvadoreños, Wood (2001) proporciona un ejemplo de gestión del miedo exitosa. Según ella, el sentimiento de orgullo por los logros alcanzados por los campesinos en su lucha les facilitó perder el miedo a la represión. La acción colectiva en sí misma contribuyó a la gestión del miedo en ese caso. La experiencia de Colina y VAR-Palmares, por su vez, no pudo contar con este elemento ya que no hubo tiempo de alcanzar logros que podrían servir como fuente de orgullo para los campesinos.

El tema del miedo está conectado a lo que Jasper and Godwin (2006) llaman de emociones morales (vergüenza u orgullo, por ejemplo), que se basan en la comprensión de lo que es correcto o incorrecto, loable o condenable: "nosotros seguimos las reglas de la moral porque tenemos miedo de las consecuencias de su subversión, o las seguimos porque nos sentimos bien haciendo lo que es correcto" (Ibid, p. 629). La mención de Alexandre a sus creencias cristianas como algo que le estimuló a no llevar a cabo el asalto que estaba siendo planeado es un ejemplo de emoción moral con interferencia en la actividad política.

Otro ejemplo es la reacción de los vecinos de Antonio en una conversación sobre el caso aquí tratado. Cuando se les preguntó si había muchas personas que participaban en las reuniones promovidas por el cura, la reacción demostró una preocupación con una posible incriminación por haber tenido algún tipo de contacto con el grupo: “iNo! Nosotros no participábamos. Tenía un amigo que participaba, pero salió” (vecinos, entrevista en el 11 de febrero de 2015, Cachoeiras de Macacu/RJ). En un contexto en el cual el anticomunismo era la perspectiva hegemónica, aún más tratándose de un gobierno represivo, la identidad de comunista era fácilmente asociada a lo moralmente condenable. Una dimensión del miedo implícita en esta reacción se comprende por el hecho de que muchos vecinos, aunque no involucrados en el grupo, acabaron siendo detenidos, quedándose en la cárcel por varios días, lo que impone el temor de que más gente pueda tener problemas con la justicia aún 
hoy. Otra dimensión es la preocupación con la preservación del honor. Si el comunismo es visto como inmoral, una eventual participación en un grupo de entrenamiento de guerrilla podría ser motivo para vergüenza o deshonra.

Roberta, por su vez, construyó su narrativa basada en la idea de que "ser un revolucionario" era algo moralmente aceptable. Al preguntarle sobre la participación de Francisco en una ocupación de tierra en $1963^{11}$, ella negó enfáticamente que su fallecido marido tuviera participado “en aquel completo desorden”. Cuando fue informada de que los documentos policiales incluían el nombre de Francisco en la lista de los participantes, Roberta reaccionó: “¡Mentira! ¡Mentira! ¡Mi marido era un revolucionario, no un vagabundo!” (Roberta, entrevista en el 18 de septiembre de 2015, Cachoeiras de Macacu/RJ). Esta frase expresa partes de la moralidad de Roberta: por un lado se percibe una visión acerca de la referida ocupación de tierra como incorrecta y, por lo tanto, fuente de vergüenza, y por otro, un entendimiento de las actividades "revolucionarias" como fuentes de honradez y orgullo.

\section{Conclusiones}

Basado en un caso específico, este documento buscó comprender las relaciones entre los militantes de las organizaciones de lucha armada y los campesinos en Brasil. El caso Colina/VAR-Palmares no se considera uno de los intentos más importantes, como los emprendidos por PCdoB en la Región Araguaia y el Movimiento Revolucionario 8 de marzo (MR-8) en Bahía, por ejemplo. Sin embargo, estudiar también otras tentativas menores es importante para comprender mejor cuán fragmentada estaba la resistencia contra la dictadura y la militancia socialista en Brasil en ese momento. Además, la profundización de un caso brinda la posibilidad de identificar los desafíos cotidianos que enfrentan los militantes y las estrategias delineadas por ellos para enfrentarlos. Aunque no es posible generalizar, las características identificadas en este caso nos permiten al menos tener una idea de cómo fue un intento de crear un grupo guerrillero.

La mayor limitación de este artículo es el hecho de que la mayoría de los campesinos que se involucraron en el proceso han fallecido. Como resultado, el análisis se basa principalmente en la perspectiva de las personas que vivieron con ellos, como las viudas o los militantes urbanos, lo que se convierte en un desafío cuando el propósito es analizar la dimensión afectiva y el compromiso político. A pesar de este obstáculo, todavía fue posible identificar algunas emociones que estimularon la participación de los campesinos: emociones recíprocas y morales, placer de la participación, esperanza, miedo y resentimiento.

Diversos actores estimularon estas emociones. Los militantes promovieron las tres primeras emociones citadas anteriormente; mientras que el Ejército fue el principal responsable por suscitar el miedo y el resentimiento. Por lo tanto, a pesar de que en la mayoría de los casos los líderes de las organizaciones son aquellos que buscan manejar las pasiones de los seguidores, a veces el propio enemigo emprende ciertas iniciativas que generan emociones que favorecerán la participación en el ámbito político.

El caso que nos ocupa es una ilustración de una circunstancia específica en la que las partes involucradas tienen diferentes antecedentes socioeconómicos: militantes de clase media urbana por un lado y campesinos subalternos por el otro. Intercambiar afecto y construir confianza entre las relaciones interpersonales fue uno de los principales desafíos para quienes intentaron formar los grupos guerrilleros. Además, superar el miedo y lidiar con los sentimientos causados por la pérdida de miembros de la familia debido a la represión también fue una tarea frecuente en este proceso.

La participación comprometida en las organizaciones de lucha armada no se explica solamente a partir de las emociones. Otros elementos relevantes son el deseo de poseer una tierra, de tener libertad política, sentir reconocimiento o, incluso,la proximidad con la violencia cotidiana y la desigualdad social en general. Sin embargo, el foco en las emociones permite deshacerse de las limitaciones de las tradicionales dicotomías (economía y política; interese y desinterese; entre otras) y comprender las acciones colectivas desde una perspectiva más compleja. 


\section{Agradecimientos}

El artículo es parte de la tesis de doctorado del autor, que cuenta con recursos de Capes y Faperj para la realización de los trabajos de campo. Una versión preliminar de este artículo fue presentada en la sesión Resistencias y Emociones en Contextos Represivos, del Comité de Investigación 48 (Movimientos Sociales, Acciones Colectivas y Cambio Social) del XIX Congreso Mundial de Sociología, realizado en Toronto, Canadá, en julio de 2018. La discusión del artículo fue coordinada por Alice Poma y Tommaso Gravante, a quienes el autor agradece por los valiosos comentarios. Registro mi agradecimiento también a Leonilde Medeiros y a Mohamed Zakzouk por las sugerencias, y a Luna Gámez, por la revisión gramatical.

\section{Notas}

${ }^{1}$ No es la intención de este trabajo discutir la legitimidad de tales organizaciones, tampoco si hayan tenido éxito o hayan fracasado, si hayan sido victoriosas o hayan sido derrotadas, si hayan provocado transformaciones positivas o negativas, sino comprender tales procesos desde un punto de vista sociológico: qué cuestiones se pueden traer a la discusión a partir del caso analizado y cómo ellas pueden ayudar a construir nuevas perspectivas de análisis para el tema de la lucha armada, la resistencia a regímenes autoritarios y la participación política del campesinado en Brasil.

${ }^{2}$ Por este motivo, no serán presentados los nombres ni de los militantes, ni de los campesinos a fin de preservarles de eventuales riesgos. En su lugar, serán utilizados nombres ficticios.

${ }^{3}$ Foquismo era un término utilizado por las izquierdas para referirse a los movimientos que creían posible hacer una revolución socialista a partir de la guerra de guerrillas y sin la participación de un partido comunista dirigente. El presupuesto era que, después de iniciadas las guerrillas, las masas acabaran adhiriendo y llegarían al poder, tal como ocurrió en Cuba. Conforme teorizó Debray (1967), una de las principales características del foquismo era su aversión al burocratismo de los partidos comunistas, que separaban la actuación política de la actuación militar, designando diferentes liderazgos para cada frente de acción. La propuesta foquista defendía que hubiera un único liderazgo, que congregase la dirección política con la militar.

${ }^{4}$ Según Gorender (1987), el principal hecho relacionado con esta organización fue, en Río de Janeiro, el intento de asesinato de Gary Prado, un capitán boliviano que arrestó a Che Guevara y fue acusado de matar al líder cubano. Prado estuvo en Brasil para un curso en la Escuela de Estado Mayor del Ejército. La idea era que su muerte honraría al movimiento revolucionario en toda América Latina. Sin embargo, el hombre que recibió los tiros no fue el militar boliviano, sino un comandante alemán, y el intento fracasó. Como se mostrará a lo largo del trabajo, perder a una persona que representó cosas importantes puede ser una fuente de emociones que estimula ciertas acciones políticas.

${ }^{5}$ En esta publicación, el general Giap, brazo derecho del líder vietnamita Ho Chi Minh, ambos muy leídos por militantes de la izquierda armada brasileña, describe algunas estrategias adoptadas por el Partido Comunista Indochino (en 1959, el nombre cambió a Partido de los Trabajadores de Vietnam) junto a la población campesina. Su principal énfasis es la importancia del partido construir una buena relación con el pueblo. Tal preocupación se expresa en uno de los nueve juramentos que los soldados estaban obligados a hacer para poder componer el ejército: "En los contactos con el pueblo, ajustarse a tres recomendaciones: respetar al pueblo, ayudar al pueblo y defender al pueblo” (Giap, 1971, p. 65).

${ }^{6}$ Además de la VAR-Palmares, otras organizaciones armadas también escogieron la región del Bico do Papagaio para reclutar campesinos porque la consideraban estratégica para la guerra de guerrillas.

${ }^{7}$ El autor basa su reflexión en las ideas de Hannah Arendt, Michel Foucault y Jacques Derrida.

${ }^{8}$ De hecho, Aristóteles ya dijo que la amistad era la principal virtud de la política y una condición para el bienestar de la ciudad, ya que el intercambio de ideas por medio del discurso unificaría a los ciudadanos y resolvería los conflictos.

${ }^{9}$ Las organizaciones armadas en Brasil a menudo se sostenían con recursos expropiados de bancos y algunas tiendas en las ciudades.

${ }^{10}$ Aminzade y McAdam (2001) apuntan para lo que llaman de "movilización de la esperanza" (mobilization of hope en el texto original), asociada a la movilización de la rabia, como una de las maneras utilizadas por los movimientos sociales para el trabajo de reclutamiento de nuevos adeptos o para mantener los ya involucrados. Romanos (2011) confirmó esta teoría en el caso de los libertarios anarquistas durante el régimen represivo de Franco en España, donde la esperanza de vitoria constituyó una emoción central para la movilización y el fortalecimiento del compromiso de los militantes.

${ }^{11}$ Se refiere a la hacienda São José da Boa Morte, área de tierras que hacía la divisa con la localidad de Nova Ribeira, donde vivían Antonio, Francisco, Roberta y los demás familiares. Esta hacienda ya había sido ocupada dos veces: en 1961 y en 1963, porque el propietario hubiera sido acusado de acaparamiento de tierras. Como resultado de la ocupación de 1963, el presidente João Goulart firmó, en enero de 1964, un decreto para expropiar la propiedad con el fin de establecer un nuevo asentamiento para los sin tierra. Sin embargo, los militares, que derrocaron al gobierno de Goulart en marzo de 64, revocaron el decreto y expulsaron a todos los campesinos que ocupaban la granja. Ver más en Silva (1994) y Teló y Braga (2015). 


\section{Bibliografía}

Aminzade, R. \&Mcadam, D. (2001). Emotions and contentious politics. En: Aminzade, R., Goldstone, J. A., McAdam, D., $\quad$ Perry, E. J., Sewell, W. H., Tarrow, S. \& Tilly, C. (Eds.) Silence and voice in contentious politics. Cambridge, UK: Cambridge University Press.

Barbalet, J. M. (1998). Emotion, Social Theory, and Social Structure: A Macrosociological Approach. Cambridge, UK: Cambridge UniversityPress.

Bohamon, S. O. (2006). Emociones y movimientos sociales: algunas claves útiles para estudiar el conflicto armado. Colombia Internacional, (63), 174 - 187.

Chacel, C. (2012). Seu amigo esteve aqui. Rio de Janeiro, Brasil: Zahar.

Debray, R. (1967).Revolution dans la revolution?Paris: Maspero.

Della Porta, D. (1995). Social Movements, Political Violence and the State: a comparative analysis of Italy and Germany. Cambridge, UK: Cambridge University Press.

(1998). Las motivaciones individuales en las organizaciones políticas clandestinas. En: P. Ibarra, \&B., Tejerina. (eds.) Los movimientos sociales. Transformaciones políticas y cambio cultural. Madrid, España: Editorial Trotta.

Dreifuss, R. A. (1981). 1964: a Conquista do Estado. Ação Política, Poder e Golpe de Classe. Petrópolis, Brasil: Vozes.

Flam, H. (2015). Micromobilization and Emotions. En: Della Porta, D.\&Diani, M. (eds.) The Oxford Handbook of Social Movements. Oxford, UK: Oxford University Press.

Giap, V. N. (1971). Guerra del Pueblo, Ejército del Pueblo. Ciudad de México, México: DR Ediciones.

Godwin, J. \&Pfaff, S. (2001). Emotion Work in High-Risk Social Movements: Managing Fear in the U.S. and East German Civil Rights Movements. In: J. Godwin, J. Jasper, \&F., Poletta, Passionate Politics: emotions and social movements. Chicago and London: The University of Chicago Press.

Godwin, J., Jasper, J. \&Poletta, F. (2001). Introduction. In: Passionate Politics: emotions and social movements. Chicago and London: The University of Chicago Press.

Goodwin, J.\& Jasper, J. (2006). Emotions and Social Movements. In: Stets, J. E.\&Turner, J. H. The Handbook of Sociology of Emotions. New York, United States: Springer.

Gorender, J. (1987). Combate nas trevas: a esquerda brasileira - das ilusões perdidas à luta armada. São Paulo, Brasil: Ática.

Jasper, J. (1998). The art of moral protest: culture, biography, and creativity in social movements. Chicago, United States: The University of Chicago Press.

Mauss, M. (2003). Sociologia e Antropologia. São Paulo, Brasil: Cosac Naify.

Ortega, F. (2000). Para uma política da amizade. Arendt, Derrida e Foucault. Rio de Janeiro, Brasil: Relume Dumará.

Quirós, J. (2009). Economia e Política na ação coletiva: uma crítica etnográfica às premissas dicotômicas. Mana15(1),127-153. https://dx.doi.org/10.1590/S0104-93132009000100005 
(2010). Por que vêm? Figuração, pessoa e experiência na política da Grande Buenos Aires. Tese (Doutorado em Antropologia Social) Museu Nacional, Universidade Federal do Rio de Janeiro.

Ridenti, M. (2010). O fantasma da revolução brasileira. São Paulo, Brasil: Unesp.

Romanos, E. (2011). Emociones, identidad y represión: el activismo anarquista durante el franquismo. Reis, (134), $87-106$.

Sales, J. R. (2005). O impacto da revolução cubana sobre as organizações comunistas brasileiras (1959-1974). Tese (doutorado). Campinas: Programa de Pós-graduação em História, Universidade Estadual de Campinas,.

Silva, L. R. (1994). Luta pela terra em São José da Boa Morte: participação política e representação social no cotidiano dos lavradores (1960 - 1964). Dissertação (Mestrado). Assis: Programa de Pós-graduação em História, Universidade Estadual Paulista Júlio Mesquita Filho.

Teló, F. \&Braga, R. (2015). Conflitos e repressão no campo em Cachoeiras de Macacu. In: Conflitos e Repressão no Campo no Estado do Rio de Janeiro (1946-1988). Relatório de Pesquisa. CPDA/UFRRJ.

Wolf, E. (1984). Guerras camponesas no século XX. São Paulo, Brasil: Global.

Wood, E. (2001). The Emotional Benefits of Insurgency in El Salvador. In: Godwin, J. \& Jasper, J. \&Poletta, F. Passionate Politics: emotions and social movements. Chicago and London: The University of Chicago Press. 